\title{
Risk Factors Assessment and Clinical Profile of Neonatal Sepsis in Blood Culture Proven Neonates.
}

\author{
Hisham A. Ismail ${ }^{{ }^{*}}$; Abd El Aziz, A. M. ${ }^{2}$; El Araby, H.A. ${ }^{2}$ and Wael S. Soliman ${ }^{1}$. \\ ${ }^{1}$ Molecular Diagnosis Department, Genetic Engineering and Biotechnology Research \\ Institute (GEBRI), Sadat City University, Egypt. \\ ${ }^{2}$ National Liver Institute, Menoufia University, Egypt. \\ Corresponding author; email; dr_hishamsadek@yahoo.com
}

\begin{abstract}
Neonatal sepsis refers to infection occurring within the neonatal period i.e. the first 28 days of life for a term baby, and up to 4 weeks beyond the expected date of delivery in a preterm baby. Neonatal sepsis is still a major cause of morbidity and mortality during the first year of life. Assessment of risk factors and clinical profile of neonatal sepsis was done on 42 cases with blood culture proved neonatal sepsis of total 102 cases with clinically suspected neonatal sepis admitted to the Neonatal Intensive Care Units (NICUs) in El Menoufia and El Kalyoubia governorates hospitals versus 30 age and sex matched healthy controls. Complication during labour, Birth weight and Gestation age were the common risk factors were associated with the development of neonatal sepsis where Respiratory distress, Lethargy, Poor feeding, abdominal distension, Apnea and Cyanosis were the most common clinical signs represent clinical profile of neonatal sepsis.
\end{abstract}

Keywords: Neonatal sepsis; Risk factors; Clinical profil; BACT/ALERT automated blood culture ystem.

\section{INTRODUCTION}

Sepsis has been called the hidden public health disaster (Angus, 2010). The international consensus definition has recently defined sepsis as" life threatening organ dysfunction caused by a dysregulated host response to infection" and septic shock as "a sub set of sepsis in which particularly profound circulatory, cellular and metabolic abnormalities are associated with a great risk of mortality than with sepsis alone" (Singer et al, 2016).

In Europe, every year, 157000 people die for this systemic multi-organs failure as a consequence of bacterial or fungal infection (Goto \& Al-Hasan; 2013). Every year 2.6 million neonates die; three fourths of deaths occur in the first week of life, and almost all (99\%) in low- and middle-income countries (Wang et al, 2014). In fact $75 \%$ of mortality occurs in developing countries is due to under-recognition of illness (Obiero et al, 2015). There are many risk factors for development of neonatal sepsis including unsafe place of delivery or unclean delivery, prolonged rupture of membranes more than 24 hours, maternal pyrexia, chorio-amnionitis (foul smelling liquor), prolonged labor and perinatal asphyxia (Khinchi et al, 2010). Maternal fever within 2 weeks prior to delivery, meconium stained amniotic fluid (MSAF) and instrumental delivery (Shah et al, 2006).

The fetal risk factors are low birth weight, gestation and Apgar score immature immune system, decreased phagocyte activity of white cells, 
decreased production of cytokines and weak humoral immunity. The natural skin barrier is thin and weak (Shah et al, 2006).

Neonatal sepsis is divided into earlyonset sepsis (if symptoms start before 72 $\mathrm{h}$ of life) and late-onset sepsis (if symptoms start afterward). Various cutoff points have been used to defined sepsis onset type, it ranges from $48 \mathrm{~h}$ to 7 days, but most epidemiological studies use 72 h (Shane\& Stoll; 2014). Earlyonset sepsis (EOS) is generally caused due to the pathogens acquired from the mother or during birth and also the vaginal tract (Kumar \& Baht, 2015).

The common risk factors for EOS include prematurity, maternal Group B Streptococcus (GBS) infection, chorioamnionitis, immunological immaturity, premature rupture of membranes, prolonged rupture of membranes (more than $18 \mathrm{~h}$ ), maternal urinary tract infections (UTI), intraamniotic infections, and multiple pregnancies (Camacho-Gonzalez et al, 2013). Although there are a number of microorganisms causing these earlyonset infections, GBS infection and Escherichia coli (E. coli) constitute about $90 \%$ of them (Fleming et al, 2012). Late-onset sepsis (LOS) is generally after $72 \mathrm{~h}$ of birth and is mainly caused by pathogens from environment, which invades through the skin and nasal channel of the newborn (Kumar \& Baht, 2015). Frequent pathogens associated with LOS are Staphylococcus aureus, Coagulase negative Staphylococci (CoNS), Haemophilus influenzae, E. coli, Klebsiella, Pseudomonas, and Candida spp (Fleming et al, 2012). In general, the most prevalent gram-positive organisms causing neonatal sepsis include Staphylococcus aureus, CoNS, Enterococcus, and Listeria monocytogenes. Other than E coli, the most common gram-negative organisms are Klebsiella, Enterobacter, Citrobacter, and Pseudomonas (Weston et al 2011).

\section{MATERIAL AND METHODS}

This study was conducted on 102 neonates suspected to have clinically diagnosed neonatal sepsis admitted to Neonatal Intensive Care Units (NICUs) in 4 distinct hospitals from Menoufia and El Kalyoubia governorates were enrolled. These NICUs and corresponding patients' numbers were:-

1- Neonatal intensive care unit (NICU),

National Liver Institute hospitalMenoufia University, from which 24 cases were included.

2- Neonatal intensive care unit (NICU), Menoufia University hospital, from which 41 cases were included.

3- Neonatal intensive care unit (NICU), Benha University hospital, from which 30 cases were included

4- Neonatal intensive care unit (NICU), Berket El Saba central hospital Ministry of Health and Population, from which 7 cases were included.

These patients were evaluated for the following risk factors:-

1- Maternal risk factors: Age of the mother, education level, socioeconomic status, Parity, mode of delivery (cesarean, vaginal, instrumental), premature rupture of the membranes (PROM), meconium stained amniotic fluid (MSAF), maternal fever in the third trimester two weeks before delivery, pregnancy induced hypertension (PIH), Pre eclamptic toxemia (PET)/ Eclampsia, foul smelling amniotic fluid, antepartum hemorrhage and maternal chronic diseases and medications

2- Fetal risk factors: Gestational age ,sex of the baby, birth weight, Apgar score at one minute, birth asphyxia and complicated labor (birth trauma, laryngeal intubation, invasive procedures) and prolonged labor.

The neonates were evaluated for the following clinical manifestations from which Clinical profile of neonatal sepsis will be concluded:- 
Respiratory distress, lethargy, fever, poor feeding, abdominal distention, apnea, vomiting, hypothermia, cyanosis, irritability and convulsions.

The sepsis work up were done and dependent on positivity of at least two of the following laboratory screening tests to identified the patients to had clinical neonatal septicemia.

The investigations are:-

i. Total leukocyte count $<5000 / \mathrm{mm} 3$ or $\geq 25,000$ at birth or $\geq 30,000-12-24 \mathrm{~h}$ or $\geq 21,000$-Day 2 onwards.

\section{Results}

In this study, from 102 clinically diagnosed neonatal sepsis, 42 cases were blood culture proven bacterial neonatal sepsis confirmed with the detection of bacterial growth with BACT/ALERT ii. Band cell count $\geq 20 \%$

iii. Micro ESR $\geq 15 \mathrm{~mm} / 1^{\text {st }}$ hour

iv. C-reactive protein $>6 \mathrm{mg} / \mathrm{dL}$

v. Absolute neutrophil count $<1500 / \mathrm{mm}^{3}$

The clinically diagnosed cases with neonatal sepsis will be undergone convential blood culture test with automated BACT/ALERT ${ }^{\circledR}$ 3D 60 instrument (BioMérieux, INC. USA) bloodculture system to confirm the diagnosis of neonatal sepsis.

automated blood culture system. Table (1) represent bacteria detected with conventional blood culture in 42 neonates out of 102 clinically diagnosed neonatal sepsis patients.

Table (1): Types of bacteria isolated with BACT/ ALERT automated blood culture system.

\begin{tabular}{|l||c|c|}
\hline \multicolumn{1}{|c||}{ Organisms } & No & percent \\
\hline \hline 1- Bacterial & 20 & $47.6 \%$ \\
Klebsiella & 5 & $11.9 \%$ \\
Staphylococcus aureus & & \\
Coagulase negative staphylococcus & & \\
(CoNs) & 3 & $7.1 \%$ \\
$\quad$ - Staphylococcus epidermedis & 2 & $4.8 \%$ \\
- CoNS & 1 & $2.4 \%$ \\
- Staphylococcus lugdunensis & 1 & $2.4 \%$ \\
Streptococcus & 2 & $4.8 \%$ \\
E coli & 3 & $7.1 \%$ \\
Enterococci & 4 & $9.5 \%$ \\
Enterobacter & 1 & $2.4 \%$ \\
Acinatobacter & 42 & $100 \%$ \\
\hline \hline
\end{tabular}


Table (2): Various maternal and neonatal risk factors in blood culture proven sepsis subgroup.

\begin{tabular}{|c|c|c|c|c|}
\hline Parameter & $\mid$ Variables & Cases $(n=42)$ & 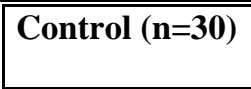 & \begin{tabular}{|l} 
Statistical \\
significance
\end{tabular} \\
\hline Maternal age & \begin{tabular}{|l|}
$<20$ \\
$\geq 20$
\end{tabular} & \begin{tabular}{|l|}
5 \\
37
\end{tabular} & \begin{tabular}{|l|}
1 \\
29
\end{tabular} & $P=0.194$ \\
\hline Educational status & $\begin{array}{l}\text { Illiterate } \\
\text { Literate or more }\end{array}$ & \begin{tabular}{|l|}
2 \\
40
\end{tabular} & \begin{tabular}{|l|}
3 \\
27
\end{tabular} & $P=0.388$ \\
\hline $\begin{array}{l}\text { Socioeconomic } \\
\text { status }\end{array}$ & $\begin{array}{l}\text { Poor } \\
\text { Moderate or more }\end{array}$ & \begin{tabular}{|l|}
0 \\
42
\end{tabular} & \begin{tabular}{|l|}
1 \\
29 \\
\end{tabular} & $P=0.233$ \\
\hline Parity & \begin{tabular}{|l|} 
Primi \\
Multi \\
\end{tabular} & \begin{tabular}{|l|}
9 \\
33 \\
\end{tabular} & \begin{tabular}{|l|}
6 \\
24 \\
\end{tabular} & $P=0.883$ \\
\hline Mode of delivery & \begin{tabular}{|l|} 
Vaginal \\
Instrumental/LCS
\end{tabular} & $\begin{array}{l}11 \\
31\end{array}$ & \begin{tabular}{|l|}
4 \\
26
\end{tabular} & $P=0.185$ \\
\hline PROM & \begin{tabular}{|l} 
Yes \\
No
\end{tabular} & \begin{tabular}{|l|}
5 \\
37
\end{tabular} & \begin{tabular}{|l|}
1 \\
29
\end{tabular} & $P=0.194$ \\
\hline MSAF & \begin{tabular}{|l|} 
Yes \\
No \\
\end{tabular} & \begin{tabular}{|l|}
1 \\
41 \\
\end{tabular} & \begin{tabular}{|l|}
1 \\
29 \\
\end{tabular} & $P=0.808$ \\
\hline Maternal fever & \begin{tabular}{|l|} 
Yes \\
No \\
\end{tabular} & \begin{tabular}{|l|}
0 \\
42 \\
\end{tabular} & \begin{tabular}{|l|l}
0 \\
30 \\
\end{tabular} & $P=0.00$ \\
\hline PIH & \begin{tabular}{|l|} 
Yes \\
No \\
\end{tabular} & \begin{tabular}{|l|}
2 \\
40 \\
\end{tabular} & \begin{tabular}{|l|}
2 \\
28 \\
\end{tabular} & $P=0.727$ \\
\hline PET/Eclampsia & \begin{tabular}{|l|} 
Yes \\
No \\
\end{tabular} & \begin{tabular}{|l|}
4 \\
38 \\
\end{tabular} & \begin{tabular}{|l|}
0 \\
30 \\
\end{tabular} & $P=0.08$ \\
\hline FSAF & \begin{tabular}{|l|} 
Yes \\
No \\
\end{tabular} & \begin{tabular}{|l|l|}
0 \\
42 \\
\end{tabular} & \begin{tabular}{|l|l|}
0 \\
30 \\
\end{tabular} & $P=0.00$ \\
\hline APH & \begin{tabular}{|l|} 
Yes \\
No \\
\end{tabular} & \begin{tabular}{|l|}
5 \\
37 \\
\end{tabular} & \begin{tabular}{|l|}
0 \\
30 \\
\end{tabular} & $P=0.05$ \\
\hline $\begin{array}{l}\text { Maternal chr.dis.\& } \\
\text { medications }\end{array}$ & \begin{tabular}{|l|} 
Yes \\
No \\
\end{tabular} & \begin{tabular}{|l|}
5 \\
37 \\
\end{tabular} & \begin{tabular}{|l|}
1 \\
29 \\
\end{tabular} & $P=0.194$ \\
\hline Birth weight & $\begin{array}{l}<2.5 \\
\geq 2.5\end{array}$ & $\begin{array}{l}21 \\
21\end{array}$ & $\begin{array}{l}7 \\
23\end{array}$ & \\
\hline Mean \pm SD $($ Grams $)$ & & $\begin{array}{l}2214.5 \pm 818.3 \\
(\mathrm{n}=42)\end{array}$ & $\begin{array}{l}2784.3 \pm 509.3 \\
(\mathrm{n}=30)\end{array}$ & $P=0.118$ \\
\hline $\begin{array}{l}\text { Apgar score (1 } \\
\text { minute) }\end{array}$ & \begin{tabular}{|l|}
$<7$ \\
$\geq 7$ \\
\end{tabular} & \begin{tabular}{|l|}
25 \\
17 \\
\end{tabular} & \begin{tabular}{|l|}
7 \\
23 \\
\end{tabular} & $P=0.002$ \\
\hline Gestation age & \begin{tabular}{|l|} 
Preterm \\
Full term
\end{tabular} & $\begin{array}{l}20 \\
22\end{array}$ & \begin{tabular}{||l}
7 \\
23
\end{tabular} & $P=0.03$ \\
\hline Mean \pm SD $($ Weeks $)$ & & $35.69 \pm 2.7$ & $37 \pm 1.66$ & $P=0.02$ \\
\hline Sex & \begin{tabular}{|l|} 
Male \\
Female \\
\end{tabular} & \begin{tabular}{|l|}
18 \\
24 \\
\end{tabular} & \begin{tabular}{|l|}
19 \\
11 \\
\end{tabular} & $P=0.08$ \\
\hline Birth asphyxia & \begin{tabular}{|l|} 
Yes \\
No \\
\end{tabular} & \begin{tabular}{|l|}
5 \\
37 \\
\end{tabular} & \begin{tabular}{|l|l|}
0 \\
30 \\
\end{tabular} & $P=0.05$ \\
\hline $\begin{array}{l}\text { Complications } \\
\text { during labour }\end{array}$ & \begin{tabular}{|l|} 
Yes \\
No \\
\end{tabular} & \begin{tabular}{|l|}
9 \\
33 \\
\end{tabular} & \begin{tabular}{|l|}
0 \\
30 \\
\end{tabular} & $P=0.006$ \\
\hline
\end{tabular}


Table (3): Clinical profile of blood culture proven sepsis subgroup.

\begin{tabular}{|c|c|c|c|c|}
\hline Parameter & Variable & Cases $(n=42)$ & 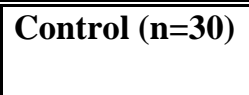 & $\begin{array}{l}\text { Statistical } \\
\text { significance }\end{array}$ \\
\hline $\begin{array}{l}\text { Respiratory } \\
\text { distress }\end{array}$ & $\begin{array}{l}\text { Yes } \\
\text { No }\end{array}$ & $\begin{array}{l}31 \\
11\end{array}$ & \begin{tabular}{|l|}
8 \\
22 \\
\end{tabular} & $\mathrm{P}<0.0001$ \\
\hline Lethargy & $\begin{array}{l}\text { Yes } \\
\text { No }\end{array}$ & $\begin{array}{l}35 \\
7\end{array}$ & \begin{tabular}{|l|}
9 \\
21
\end{tabular} & $\mathrm{P}<0.0001$ \\
\hline jaundice & \begin{tabular}{|l} 
Yes \\
No
\end{tabular} & $\begin{array}{l}35 \\
7\end{array}$ & \begin{tabular}{|l|}
29 \\
1
\end{tabular} & $P=0.07$ \\
\hline Fever & $\begin{array}{l}\text { Yes } \\
\text { No }\end{array}$ & $\begin{array}{l}6 \\
36 \\
\end{array}$ & \begin{tabular}{|l|}
2 \\
28 \\
\end{tabular} & $P=0.31$ \\
\hline Poor feeding & $\begin{array}{l}\text { Yes } \\
\text { No }\end{array}$ & $\begin{array}{l}39 \\
3\end{array}$ & \begin{tabular}{|l|}
8 \\
22
\end{tabular} & $\mathrm{P}<0.0001$ \\
\hline $\begin{array}{l}\text { Abdominal } \\
\text { distension }\end{array}$ & $\begin{array}{l}\text { Yes } \\
\text { No } \\
\end{array}$ & $\begin{array}{l}23 \\
19 \\
\end{array}$ & \begin{tabular}{|l|}
3 \\
27 \\
\end{tabular} & $P<0.0001$ \\
\hline Apnea & $\begin{array}{l}\text { Yes } \\
\text { No }\end{array}$ & $\begin{array}{l}18 \\
24\end{array}$ & \begin{tabular}{|l|}
1 \\
29
\end{tabular} & $P=0.0002$ \\
\hline Vomiting & $\begin{array}{l}\text { Yes } \\
\text { No }\end{array}$ & $\begin{array}{l}4 \\
38\end{array}$ & $\begin{array}{l}1 \\
29\end{array}$ & $P=0.308$ \\
\hline Hypothermia & $\begin{array}{l}\text { Yes } \\
\text { No }\end{array}$ & $\begin{array}{l}1 \\
41\end{array}$ & \begin{tabular}{|l|}
0 \\
30
\end{tabular} & $P=0.394$ \\
\hline Cyanosis & $\begin{array}{l}\text { Yes } \\
\text { No }\end{array}$ & $\begin{array}{l}20 \\
22 \\
\end{array}$ & \begin{tabular}{|l|}
1 \\
29 \\
\end{tabular} & $\mathrm{P}<0.0001$ \\
\hline Irritability & $\begin{array}{l}\text { Yes } \\
\text { No }\end{array}$ & $\begin{array}{l}2 \\
40\end{array}$ & \begin{tabular}{|l|}
0 \\
30 \\
\end{tabular} & $P=0.225$ \\
\hline Convulsions & $\begin{array}{l}\text { Yes } \\
\text { No }\end{array}$ & $\begin{array}{l}0 \\
42 \\
\end{array}$ & \begin{tabular}{|l|}
0 \\
30 \\
\end{tabular} & $P=0.00$ \\
\hline
\end{tabular}

Table 2 represents statistically significant maternal and fetal risk factors associated with the development of neonatal sepsis. The significant risk factors were birth weight, gestational age including its mean $\pm \mathrm{SD}$, Apgar score at 1 minute after birth and complication during labour.

\section{Discussion}

Our study was designed to detect maternal and fetal risk factors associated with the development of neonatal sepsis and its clinical profile in blood culture proven neonatal sepsis patients.
Table 3 represents statistically significant clinical signs and symptoms associated with neonatal sepsis. These significant signs and symptoms were respiratory distress, lethargy, poor feeding, abdominal distension, apnea and cyanosis.

From 102 clinically diagnosed neonatal sepsis patients, blood culture proven neonatal sepsis were detected in 42 cases. The bacteria which were isolated 
and its corresponding cases numbers were shown in Table (1).

Klebsiella microorganism were the most frequent bacteria isolated from clinically diagnosed neonatal sepsis patients; in 20 cases represent $47.6 \%$ of 42 blood culture proven sepsis patients. In study by Kayange et al, it was reported that Klebsiella pneumoniae was the commonest isolate recovered from infected neonates (Kayange et al, 2010). Also, in tertiary care institutions in India, Klebsiella pneumoniae is the most frequent bacterial isolate, followed by Staphylococcus aureus (Tripathi \& Malik, 2010). CoNS were isolated from 6 cases represent $14.3 \%$ of 42 blood culture proven sepsis patients Table (1). The CoNS isolates were 6 cases; 3 cases for Staphylococcus epidermedis, one case for Staphylococcus lugdunensis and 2 cases were ill defined CoNS bacteria. CoNS infections in neonatal sepsis are usually secondary to Staphylococcus epidermidis, other strains such as Staphylococcus capitis, Staphylococcus haemolyticus, and Staphylococcus hominis have also been reported (Camacho-Gonzalez et al, 2013). There was an important role of CoNS as pathogens in neonatal infections has been recognized (Piette \& Verschraegen, 2009). Staphylococcus aureus was isolated from 5 cases represents $11.9 \%$ of 42 blood culture proven sepsis patients Table (1). $S$ aureus causes blood stream infections and sepsis, skin and/or soft-tissue/wound infections, osteoarthritis (which can be multifocal), and less commonly, central nervous system infections such as meningitis and ventriculitis (Polin \& Saiman, 2003). Enterobacter were isolated from 4 cases which represent $9.5 \%$ of 42 blood culture proven sepsis patients Table (1). Enterobacter spp, such as E cloacae, E agglomerans, and $E$ sakazakii, are less common causes of hospital-acquired infections in NICUs. Enterobacter spp are multi-drug resistant pathogens and can cause sepsis and meningitis in preterm infants. Infections with these pathogens are associated with high mortality rates (Polin and Saiman, 2003). Enterococci was isolated from 3 cases which represents $7.1 \%$ of 42 blood culture proven sepsis patients Table (1). Enterococcal EOS is usually mild compared with LOS and is characterized by either a mild respiratory illness or diarrhea without a focal infection. Enterococcus faecalis is more frequently isolated than Enterococcus faecium (Camacho-Gonzalez et al, 2013).

Escherichia coli was isolated from 2 cases which represent $4.8 \%$ of 42 blood culture proven sepsis patients Table (1). Epidemiologic surveillance has noted the 
emergence of E. coli as an important pathogen associated with EOS, especially among VLBW infants (Shane \& Stoll, 2014). Streptococcus and Acintobacter; was isolated in one case which represent $2.4 \%$ of 42 blood culture proven sepsis patients for each bacteria Table (1). GBS remains the most frequent pathogen of early-onset infection, there has been a shift from GBS to E. coli as the most important pathogen associated with early-onset infection in preterm and very low birthweight infants. Maternal GBS bacteriuria, indicative of a heavy burden of GBS colonisation, represents a notable risk for acquisition of neonatal GBS infection (Shane et al, 2017).

In this study, low birth weight and gestational age were significant risk factors for the development of neonatal sepsis. The incidence rate of neonatal sepsis is 3- to10-fold higher in preterm infants than in full term normal birth weight infants (Stoll, 2007). The incidence rate of nosocomial infections is more much higher among preterm infants $<1500 \mathrm{~g}$, admitted at Neonatal Intensive Care Units (NICUs) (20-25\%) and increases with decreasing gestational age and birth weight and has been reported to be $43 \%$ for infants of 401 $750 \mathrm{~g}, 28 \%$ for infants $751-1000 \mathrm{~g}, 15 \%$ for infants 1001-1250 $\mathrm{g}$ and $7 \%$ for infants 1251-1500 grams (Stoll, 2007). In addition to, low birth weight (LBW, $<2500 \mathrm{gms}$ ), has been associated with an increased risk of EOS (Tripathi\& Malik, 2010). Agar score at one minute after birth was a significant risk factor for the development of neonatal sepsis. this was in agree with, Palazzi et al, who stated that, Fetal distress may be one of the earliest signs of sepsis even before delivery in an infected fetus. Fetal tachycardia in the second stage of labour and a low Apgar score at birth have also been associated with peripartum infections (Palazzi et al, 2006). A low Apgar score, has been correlated with sepsis and associated adverse outcomes in the neonatal period (Roper et al, 2007). Complications during labour were a significant risk factor for the development of neonatal sepsis. These complications may include, preterm labor, premature rupture of the membranes at any time during gestation, prolonged rupture of membranes, chorioamnionitis, prolonged labor, intrauterine scalp electrodes, and traumatic delivery are factors were associated with neonatal sepsis (Nizet \& Klein, 2010). Procedures during pregnancy, such as cervical cerclage and amniocentesis, which disrupt the integrity of amniotic cavity, may also increase the rates of intra-amniotic 
infection and subsequent neonatal sepsis

(Simonsen et al, 2014).

The significant signs and symptoms of neonatal sepsis were respiratory distress, lethargy, poor feeding, abdominal distension, apnea and cyanosis Table (2).

Respiratory distress and apnea were a significant clinical signs associated with blood culture proven neonatal sepsis. Initial symptoms of neonatal sepsis might be few and could include apnoea alone or tachypnoea with retractions, nasal flaring, grunting, or tachycardia (Shane et al, 2017). Respiratory distress include tachypnea, grunting, nasal flaring, and retraction of respiratory muscles can be the sole manifestation of neonatal sepsis with or without pneumonia and can be confused with transient tachypnea (TTN) of newborn initially (Martin et al, 2011). Also, lethargy was a significant clinical sign associated with blood culture proven neonatal sepsis. Lim et al. reported a high incidence of "poor activity," presumably lethargy and increased respiratory effort in the presence of respiratory distress ( $\mathbf{L i m}$ et al, 2012). Poor feeding was a significant clinical symptom associated with neonatal sepsis in Infant with neonatal sepsis may have poor feeding, temperature instability, irritability, lethargy, respiratory distress, apnea, abdominal distension, jaundice, and/or tachycardia (Stoll et al, 2011). Abdominal distension was a significant clinical sign associated with blood culture proven neonatal sepsis. Abdominal distension is a common feature of generalized sepsis and is usually secondary to functional ileus, though must be distinguished from necrotizing enterocolitis (NEC). Abdominal palpation may be uncomfortable for the baby, especially if the abdomen is tense. Bowel sounds may be relatively silent in both NEC and functional ileus. An abdominal $\mathrm{X}$ rays radiograph (AXR) may be helpful in the differentiation between septic ileus and NEC (Bedford Russell, 2015). Cyanosis was a significant clinical sign associated with blood culture proven neonatal sepsis. Cardiac symptoms of neonatal sepsis may include cyanosis, oxygen desaturation, bradycardia, poor perfusion, reduced capillary refill, and hypotension. It is important to realize that subtle changes in respiratory status of newborns, temperature instability, or feeding problems can be the first signs of a life-threatening infection (Simonsen et al, 2014). Preterm infants will often have apnea, bradycardia, and cyanosis as the first sign of infection (Lim et al, 2012).

\section{Conclusions}


the most frequent bacteria isolated with conventional blood culture was Klebsiella which represent $47.6 \%$ of bacteria detected in blood culture proven neonatal sepsis patients. Followed by CONS, S. aureus, Enterobacter, Enterococci, E coli, Streptococci and Acinatobacter which represent $14.3 \%$, $11.9 \%, 9.5 \%, 7.1 \%, 4.8 \%, 2.4 \%$ and $2.4 \%$ respectively. The common risk factors associated with the development

\section{References}

- Angus DC. The lingering consequences of sepsis: a hidden public health disaster?. JAMA 2010; 304:1833-1834.

- Bedford Russell A R. Neonatal sepsis. pedatrics and child health 2015; 25(6): 271275.

- Camacho-Gonzalez A, Spearman P W, Stoll B J. Neonatal Infectious Diseases Evaluation of Neonatal Sepsis. Pediatr Clin $N A m$ 2013(article in press): 1-23.

- Fleming P, Forster D, Savage T, Sudholz H, Jacobs S, Daley A. Evaluating suspected sepsis in term neonates. J Neonat Nur 2012; $18: 98104$.

- Goto M, Al-Hasan MN. Overall burden of bloodstream infection and nosocomial bloodstream infection in North America and Europe. Clin Microbiol Infect 2013; 19(6): 501-9.

- Khinchi Y R, Kumar A, Yadav S. Profile of Neonatal sepsis. Journal of college of Medical Sciences-Nepal 2010;6(2): 1-6.

- Kumar K M and Bhat B V. Current challenges and future perspectives in neonatal sepsis. pediatric infectious disease $2015 ; 741-746$. of neonatal sepsis in blood culture proven sepsis patients were gestational age, low birth weight, Agar score at one minute and complications during labour while respiratory ditress, apnea, letharg, poor feeding, abdominal distension and cyanosis were the significant clinical sign and symptoms.

- Lim WH, Lien R, Huang YC, et al. Prevalence and pathogen distribution of

neonatal sepsis among very-low-birthweight infants. Pediatr Neonatol 2012; 53:228-234.

- Martin RJ and Fanaroff AA, Walsh MC. Fanaroff and Martin's neonatal-perinatal medicine: diseases of the fetus and infant. Philadelphia: Saunders/Elsevier, 2011.

- Nizet V, Klein JO. Bacterial Sepsis and Meningitis. In: Infectious Diseases of the Fetus and Newborn Infant. Eds. Remington JS, Klein JO, Wilson CB and Baker CJ. 7th Edn. Philadelphia PA: Elsevier Saunders. 2010; 225-278.

- Obiero C W, Seale A C, Berkley J A. Empiric Treatment of Neonatal Sepsis in Developing Countries. The Pediatric Infectious Disease Journal 2015; 34 (6):659-661.

- Palazzi DL, Klein JO, Baker CJ. Bacterial Sepsis and Meningitis. In: Infectious Diseases of the Fetus and Newborn Infant. Eds. Remington JS, Klein JO, Wilson CB 
and Baker CJ. 6th Edn. Philadelphia PA:

Elsevier Saunders. 2006; 247-296.

- Piette A and Verschraegen G. Role of coagulase-negative staphylococci in human disease. Vet Microbiol 2009. 134(1-2): p. 4554.

- Polin R A and Saiman L. Nosocomial Infections in the Neonatal Intensive Care Unit. NeoReviews 2003;4 (3): e81-e89.

- Roper MH, Vandelaer JH, Gasse FL. Maternal and neonatal tetanus. Lancet 2007; 370: 1947-1959.

- Shah GS, Budhathoki S, Das BK, Mandal RN. Risk factors in early neonatal sepsis. Kathmandu University medical journal 2006;6(2):187-191.

- Shane A L, Sánchez P J, Stoll B J. Neonatal sepsis. Lancet 2017:1-11.

- Shane AL and Stoll BJ. Neonatal sepsis: progress towards improved outcomes. $J$ Infect 2014;68:S24-32.

- Simonsen K, Anderson-Berry A, Delair S, Davies HD. Early onset neonatal sepsis. Clin Microbiol Rev 2014;27:21-47.

- Singer M, Deutschman CS, Seymour CW, et al. the third international consensus definitions for sepsis and septic shock (sepsis 3). JAMA 2016;315(8):801-810.

- Stoll BJ, Hansen NI, Sanchez PJ, et al. Eunice Kennedy Schriver National Institute of Child Health and Human Development Neonatal Research Network. Early onset neonatal sepsis: the burden of group B streptococcal and E. coli disease continues. Pediatrics 2011;127:817-26.

- Stoll BJ. Infections of the neonatal infant. In: "Kliegman", “Behrman”, “Jenson”,
"Stanton", ed. 18th ed. Philadelphia: Saunders Elsevier; 2007:794-811.

- Tripathi S and Malik G. K. Neonatal Sepsis: past, present and future; a review article. Internet Journal of Medical Update 2010; $5(2): 45-54$.

- Wang H, Liddell CA, Coates MM, et al. Global, regional, and national levels of neonatal, infant, and under-5 mortality during 1990-2013: a systematic analysis for the Global Burden of Disease Study 2013. Lancet 2014; 384:957-79.

- Weston EJ, Pondo T, Lewis MM, et al. The burden of invasive early-onset neonatal sepsis in the United States, 2005-2008. Pediatr Infect Dis J 2011;30:937-41. 
